\title{
ATIVIDADE ANTIMICROBIANA IN VITRO DE EXTRATOS ETANÓLICOS DE PRÓPOLIS DE TRÊS ESTADOS BRASILEIROS SOBRE AEROMONAS HYDROPHILA ISOLADAS DE PEIXES
}

\author{
N.P.C. Andrade ${ }^{1}$, E.M.S da Silva ${ }^{1}$, R.A. Mota ${ }^{2}$, \\ J.L.A. Veschi ${ }^{3}$, M.F. Ribeiro ${ }^{3}$, C.C. Krewer ${ }^{1}$, M.M. da Costa ${ }^{1}$
}

${ }^{1}$ Universidade Federal do Vale do São Francisco, Colegiado de Zootecnia, Rodovia BR 407, km 12, Lote 543, Projeto de Irrigação Nilo Coelho, s/n C1, CEP 56300-000, Petrolina, PE, Brasil. E-mail: naraegabriel@ hotmail.com

\section{RESUMO}

\begin{abstract}
Opresente estud teve como objetivo avaliar a sensibilidade invitro de Aeromonas hydrophila frente a extratos etanólicos de própolis (uma verde e duas marrons) obtidos em três estados brasileiros (Minas Gerais, Ceará e Pernambuco). Para verificar a atividade antimicrobiana in vitro da própolis, 15 isolados de A. hydrophila foram testados para determinar a Concentração Bactericida Mínima (CBM) dos extratos. Curvas de sobrevivência para o crescimento bacteriano foram determinadas pela incubação dos isolados em extratos etanólicos de própolis a 15\% por 24 horas. As médias da CBM dos extratos de própolis foram 1,68\% para a própolis verde, 2,31\% para a própolis marrom do Ceará e 3,75\% para a própolis marrom de Pernambuco. A curva de sobrevivência dos isolados demonstrou uma inibição parcial com até três horas de incubação. Este resultado é compatível com o efeito bacteriostático da própolis, o que pode ser de interesse para a terapia em aquicultura, como alternativa às poucas drogas antimicrobianas disponíveis.
\end{abstract}

PALAVRAS-CHAVE: Aquicultura, A. hydrophila, apicultura, resistência, própolis.

\begin{abstract}
EVALUATION OF ETHANOLIC EXTRACTS OF PROPOLIS FROM THREE BRAZILIAN STATES FOR IN-VITRO ANTIMICROBIAL ACTIVITY ON AEROMONAS HYDROPHILA ISOLATED FROM FISH. The present study was aimed to evaluate the in-vitro susceptibility of Aeromonas spp. to ethanolic extracts of propolis (one green and two brown) from three Brazilian states (Minas Gerais, Ceará and Pernambuco). In order to verify the antimicrobial activity of the propolis in vitro, 15 Aeromonas spp. isolates were tested to determine the minimal bactericidal concentration (MBC) of the extracts. Ethanol at 70\% was used as a control. Survival curves for the bacterial growth were determined by incubation of the isolates in ethanolic extracts of propolis at $15 \%$ for 24 hours. The averages of the MBC of propolis extracts were $1.68 \%$ for the green propolis of Minas Gerais, 2.31\% for the brown propolis of Ceará, and 3.75\% for the brown propolis of Pernambuco. The survival curve of the isolates showed partial inhibition until three hours of incubation. This result is compatible with the bacteriostatic effect of propolis that may be useful to antibiotic therapy in aquaculture, as an alternative to few available antimicrobial drugs.
\end{abstract}

KEY WORDS: Aquaculture, A. hydrophila, apiculture, resistance, propolis.

\section{INTRODUÇÃO}

A aquicultura é a atividade zootécnica de grande crescimento mundial (TsUKAMOTO; TAKAHASHI, 1992). A piscicultura intensiva pode proporcionar o aumento da prevalência de enferminades nos sistemas de produção inclusive no Brasil (COSTA, 2003). As bactérias disseminadas no ambiente aquático são patógenos oportunistas e podem infectar os peixes quando eles se encontram em condições desfavoráveis (BARJA; EsTEVES, 1988). As bactérias Aeromonas hydrophila, Pseudomonas fluorescens, Vibrio anguillarum e Edwardsiella tarda fazem parte do ambiente aquático, da pele, brânquias e intestino dos peixes (Plumb, 1994). Aeromonas spp. sãoconsideradas bactérias patogênicas para várias espécies de peixes e sua resistência aos beta-lactâmicos é crescente (SAAVEDRA et al., 2004).

${ }^{2}$ Universidade Federal Rural de Pernambuco, Departamento de Medicina Veterinária, Recife, PE, Brasil.

${ }^{3}$ Embrapa Semiárido - CPATSA, Petrolina, PE, Brasil. 
Ouso indiscriminado de drogas antimicrobianas, tanto para a terapia de doenças, como para promoção decrescimento, seleciona bactérias resistentes. Além da seleção natural de bactérias resistentes após a morte das sensíveis, há também a possibilidade da transferência dos genes de resistência às outras que nunca foram expostas a tal antibiótico (VERSCHUERE et al., 2000). Segundo FRANCO et al. (2007), estudos na elaboração de novos aditivos têm sido realizados na intenção de substituir estes promotores de crescimento.

As abelhas possuem capacidade seletora, sendo que coletam as resinas de que necessitam das plantas. Estas resinas possuem um eficiente poder protetor, uma vez que contêm produtos de elevadas qualidades antimicrobianas e imunológicas. A própolis constitui-se um exemplo de extrato de origem vegetal, elaborado de forma natural pelas abelhas (Apis mellifera) para vedar aberturas e controlar microorganismos em suas colônias (CUETO, 1989).

Devido à atividade biológica como substância antioxidante, anti-inflamatória, antiviral, antifúngica, antimicrobiana e antitumoral, a própolis vem sendo utilizada na medicina tradicional desde a antiguidade (KUJUMGIEV et al., 1999; BANSKOTA et al., 2000; SFORCIN et al., 2000; MARCUCCI et al., 2001). A própolis pode substituir ou reduzir o uso de drogas antimicrobianas na área zootécnica por ter a vantagem de ser um produto natural (GARCIA et al., 2004a). Dentre as propriedades biológicas da própolis, a antimicrobiana tem sido a mais estudada. Autores afirmam que a própolis éativa principalmentecontra bactérias Gram positivas e tem atividade limitada contra bactérias Gram negativas (GARCIA et al., 2004a).

Estudos com finalidade de esclarecer o efeito dos extratos de própolis contra Aeromonas spp. são necessários para utilizá-la como uma alternativa antibioticoterápica. Segundo AKINBOwale et al. (2006) e CABELLo (2006), o uso contínuo de antibióticos tem sido associado a riscos ao meio ambiente e à saúde pública. Assim, a substituição desses por produtos naturais torna-se importante. O objetivo deste trabalho foi avaliar a sensibilidade in vitro de 15 isolados de Aeromonas spp. obtidos de peixes frente a extratos etanólicos de própolis de três estados brasileiros.

\section{MATERIAL E MÉTODOS}

\section{Local}

Os isolados de A. hydrophila, obtidos de peixes, eram pertencentes à bacterioteca do Laboratório de Microbiologia e Imunologia Animal da Universidade Federal do Vale do São Francisco (UNIVASF), Campus Ciências Agrárias, Petrolina, PE.
A própolis verde foi coletada em Minas Gerais (PV) e as marrons, respectivamente, nos estados do Ceará (PMCE) e Pernambuco (PMPE).

\section{Preparo do extrato de própolis}

Foram preparados extratos etanólicos da própolis verde e das própolis marrons através do padrão oficial para o extrato conforme metodologia descrita na Instrução Normativa $n^{\circ} 3$, de 19/01/2001, do Departamento de Inspeção de Produtos de Origem Animal, do Ministério da Agricultura, Pecuária e Abastecimento (maceração a frio de $300 \mathrm{~g}$ de própolis bruta em $700 \mathrm{~mL}$ de etanol 70\%) (BRASIL, 2001). A preparação foi estocada em temperatura ambiente e protegida da luz por um período de 45 dias. Após este período, o extrato foi filtrado com o auxílio de um funil efiltro de papel previamente autoclavados. Os extratos foram então mantidos refrigerados em frascos âmbar até sua utilização.

\section{Teste da atividade antimicrobiana in vitro}

A determinação da atividade antimicrobiana in vitro dos extratos de própolis para bactérias aeróbicas seguiu descrições do protocolo M7-A7 do Clinical and Laboratory Standards Institute (CLINICAL..., 2006). Os extratos previamente preparados (300.000 $\mu \mathrm{g} / \mathrm{mL})$ foram diluídos em $200 \mu \mathrm{L}$ (1:2) de caldo Muller-Hinton (MH) utilizando microplacas, nas proporções $150.000 \mu \mathrm{g} / \mathrm{mL}, 75.000 \mu \mathrm{g} /$ $\mathrm{mL}, 37.500 \mu \mathrm{g} / \mathrm{mL}, 18.750 \mu \mathrm{g} / \mathrm{mL}, 9.375 \mu \mathrm{g} / \mathrm{mL}$, $4.685,50 \mu \mathrm{g} / \mathrm{mL}, 2.343,75 \mu \mathrm{g} / \mathrm{mL}$ e $1.171,87 \mu \mathrm{g} /$ $\mathrm{mL}$. Para verificar o efeito antimicrobiano associado ao etanol $70 \%$ e não a própolis, esse composto foi submetido às mesmas diluições da própolis. $\mathrm{Na}$ preparação do inóculo, colônias bacterianas em solução salina foram utilizadas para a obtenção de uma suspensão com turvação equivalente a escala 0,5 de Mac Farland $\left(10^{6}\right.$ Unidades Formadoras de Colônia). Desta suspensão foram transferidos 100 $\mu \mathrm{L}$ para o tubo contendo 9,9 mL também de solução salina, sendo que $10 \mu \mathrm{L}$ ( $10^{4} \mathrm{UFC}$ ) foram colocados em cada poço contendo a diluição dos extratos de própolis. As placas foram incubadas a $27^{\circ} \mathrm{C}$ por 24h. Após esse período, foi retirada uma alíquota de $10 \mu \mathrm{L}$ de cada poço e semeada na superfície de ágar $\mathrm{MH}$ incubando-a novamente por mais $24 \mathrm{~h}$ a $27^{\circ} \mathrm{C}$, para determinação da Concentração Bactericida Mínima (CBM), que foi considerada como a menor concentração dos extratos etanólicos em estudo capaz de causar a morte do inóculo, sendo esta deteminada pelo não crescimento do inóculo no ágar. Os ensaios foram realizados em triplicata. Como controle, os isolados foram semeados em caldo $\mathrm{MH}$, bem como foi utilizado caldo $\mathrm{MH}$ sem inóculo, conforme descrições da CLSI (2006). 


\section{Curva de sobrevivência}

Para preparação dos inóculos, colônias bacterianas em solução salina foram utilizadas na obtenção de uma suspensão com turvação equivalente ao tubo 0,5 da escala de Mac Farland. De cada suspensão foram transferidos $100 \mu \mathrm{L}\left(10^{6} \mathrm{UFC}\right)$ para os respectivos tubos contendo 9,9 mL também de solução salina, $1 \mathrm{~mL}$ a suspensão de cada bactéria foi inoculado em cada um de uma série de 5 tubos contendo $3 \mathrm{~mL}$ de brain heart infusion (BHI) previamente autoclavados. No $1^{\circ}$ tubo foram adicionados $150 \mu \mathrm{L}$ do extrato da própolis marrom do Estado de Pernambuco, no $2^{\circ}$ a mesma quantidade do extrato do Estado do Ceará, no $3^{\circ}$ o da própolis verde do Estado de Minas Gerais, no $4^{\circ}$, o etanol $70 \%$ e no $5^{\circ}$ apenas o caldo BHI como controle. Após esse processo, retirou-se $1 \mathrm{~mL}$ com 3 , 12 e 24 horas de incubação de cada tubo e colocados em tubos contendo $9 \mathrm{~mL}$ de solução salina fazendo assim uma diluição decimal até $10^{-5}$. Na sequência, foi retirado $1 \mathrm{~mL}$ de cada tubo e semeados em placas de Petri, em ágar padrão de contagem (PCA). As semeaduras foram realizadas em duplicata. Após incubação de $24 \mathrm{~h}$ a $27^{\circ} \mathrm{C}$, o número de UFC foi determinado.

\section{Análise estatística}

Para a curva de sobrevivência o delineamento experimental foi inteiramente casualisado em arranjo fatorial de 15 isolados de $A$. hydrophila $\times$ cinco condições (BHI, BHI + etanol 70\%, PV, PMCE e PMPE) e três repetições. Nas comparações foi utilizada análise de variância (programa Statistica, v. 5.0), sendo considerado o valor de significância de $\mathrm{P}<0,05$.

\section{RESULTADOS}

\section{Concentração Bactericida Mínima (CBM) dos diferentes extratos de própolis}

Os 15 isolados de Aeromonas spp. foram sensíveis aos extratos etanólicos dos três tipos de própolis. As Concentrações Bactericidas Mínimas dos extratos de própolis encontram-se descritas na Tabela 1. A própolis verde foi a que apresentou maior atividade com uma CBM média de 16.935,50 $\mu \mathrm{g} / \mathrm{mL}$, sendo esta menor do que as apresentadas pelas própolis marrons.

\section{Curva de sobrevivência bacteriana frente aos extratos de própolis}

A análise da curva de sobrevivência das bactérias frente aos extratos de própolis demonstrou que redução nas contagens de UFC dos isolados somente foi observada nas primeiras três horas de incubação (Tabela 2).

Tabela 1 - Concentração Bactericida Mínima (CBM) dos extratos de própolis (verde, marrom do Estado do Ceará e marrom do Estado de Pernambuco) frente aos isolados de A. hydrophila obtidas de peixes.

\begin{tabular}{|c|c|c|}
\hline \multirow[t]{2}{*}{ Própolis } & \multicolumn{2}{|c|}{$\begin{array}{c}\text { Concentração Bactericida Mínima } \\
\text { (CBM) }(\mu \mathrm{g} / \mathrm{mL})\end{array}$} \\
\hline & Variação & Média \\
\hline PV (MG) & $4,685,50-37.500$ & $16.935,50$ \\
\hline PM (CE) & $9.375-37.500$ & $23.288,29$ \\
\hline PM (PE) & $18.750-75.000$ & 37.500 \\
\hline
\end{tabular}

Legenda: PV: Própolis Verde do Estado de Minas Gerais, PMCE: Própolis Marrom do Estado do Ceará, PMPE: Própolis Marrom do Estado de Pernambuco.

Tabela 2 - Contagem de Unidades formadoras de colônia (UFC) por $\mathrm{mL}$ x $10^{6}$ de isolados de A. hydrophila em BHI, BHI + etanol 70\% e extratos etanólicos de própolis (verde, marrom do Estado do Ceará e Estado de Pernambuco) em três horas.

\begin{tabular}{|c|c|c|c|c|c|}
\hline \multirow{2}{*}{ Isolado } & \multicolumn{5}{|c|}{3 horas } \\
\hline & PMCE & PMPE & PV & $\mathrm{Al}$ & $\mathrm{BHI}$ \\
\hline P4 & 0,231Aab & $0,024 \mathrm{Dab}$ & $0 \mathrm{~Eb}$ & 0,061Bab & 0,029Ca \\
\hline P8 & 0,188Aabc & 0,083Bab & 0,017Bab & 0,189Aab & 0,028Ca \\
\hline P18 & 0,020Abcd & 0,013Cab & $0,011 \mathrm{Dbc}$ & 0,018A,Bab & 0,017Ba \\
\hline P19 & 0,030Abcd & 0,038Aab & $0,004 \mathrm{Bbc}$ & 0,048Aab & $0,149 \mathrm{Aa}$ \\
\hline P22 & 0,559Ba & $0,022 \mathrm{Dab}$ & 0,469Ca & $0,620 \mathrm{Aab}$ & $0,523 \mathrm{Ba}$ \\
\hline P25 & $0,023 \mathrm{Bbcd}$ & 0,099Aa & $0,003 \mathrm{Cbc}$ & 0,024Bab & $0,082 \mathrm{Aa}$ \\
\hline P34 & 0,019ABcd & 0,035ABab & $0,003 \mathrm{Bc}$ & $0,009 \mathrm{ABb}$ & $13,402 \mathrm{Aa}$ \\
\hline P37 & $0,012 b$ & $0,028 \mathrm{ab}$ & $0,002 b c$ & $277,773 a$ & $0,014 a$ \\
\hline P38 & 0,030ABbcd & $0,052 \mathrm{Aab}$ & $0,008 \mathrm{Bbc}$ & $0,013 \mathrm{ABb}$ & 0,030ABa \\
\hline P47 & $0,018 \mathrm{~cd}$ & $0,025 a b$ & $0,006 b c$ & $0,010 \mathrm{~b}$ & $0,034 a$ \\
\hline P78 & $0,007 \mathrm{Bd}$ & $0,043 \mathrm{ABab}$ & $0,005 \mathrm{Bbc}$ & $0,010 \mathrm{Bb}$ & $0,103 \mathrm{Aa}$ \\
\hline P79 & $0,005 d$ & $0,021 b$ & $0,006 \mathrm{~b}$ & $0,043 a b$ & $0,046 a$ \\
\hline P80 & $0,028 \mathrm{bcd}$ & $0,016 \mathrm{ab}$ & $0,023 \mathrm{ab}$ & $0,025 \mathrm{ab}$ & $0,029 a$ \\
\hline P82 & 0,095ABbcd & 0,020Aa & $0,003 \mathrm{Bbc}$ & $0,004 \mathrm{ABb}$ & 0,016ABa \\
\hline P83 & $0,017 \mathrm{~cd}$ & $0,023 \mathrm{ab}$ & $0,009 c$ & $0,015 b$ & $0,030 \mathrm{a}$ \\
\hline
\end{tabular}


Tabela 3 - Contagem de Unidades formadoras de colônia (UFC) por $\mathrm{mL} \times 10^{6}$ de isolados de A. hydrophila em BHI, BHI + etanol 70\% e extratos etanólicos de própolis (verde, marrom do Estado do Ceará e Estado de Pernambuco) em 12 horas.

\begin{tabular}{|c|c|c|c|c|c|}
\hline \multirow{2}{*}{ Isolado } & \multicolumn{5}{|c|}{12 horas } \\
\hline & PMCE & PMPE & PV & $\mathrm{Al}$ & $\mathrm{BHI}$ \\
\hline $\mathrm{P} 4$ & $916,667 \mathrm{Cab}$ & $1111,200 \mathrm{Aa}$ & 2,216Eabc & $5,675 \mathrm{Da}$ & $977,133 \mathrm{Ba}$ \\
\hline P8 & $104,100 \mathrm{Ecd}$ & $820,633 \mathrm{Aa}$ & $150,933 \mathrm{Dab}$ & $425 \mathrm{Ca}$ & 664Ba \\
\hline P18 & $307,800 \mathrm{Cbc}$ & $804,833 \mathrm{Aa}$ & $5,230 \mathrm{Eabc}$ & $59,040 \mathrm{Da}$ & $405,800 \mathrm{Ba}$ \\
\hline P19 & $490,333 \mathrm{Bb}$ & $964,333 \mathrm{Aa}$ & $52,650 \mathrm{Dab}$ & $86,163 \mathrm{Ca}$ & $988,100 \mathrm{Aa}$ \\
\hline P22 & 0,517Ce & $0,018 \mathrm{Ec}$ & $0,405 \mathrm{Dbc}$ & $5,825 \mathrm{Aa}$ & $5,29 \mathrm{Bb}$ \\
\hline P25 & $1954,000 \mathrm{Aa}$ & $736,833 \mathrm{Da}$ & $302,733 \mathrm{Ea}$ & $968,500 \mathrm{Ca}$ & $1551,633 \mathrm{Ba}$ \\
\hline P34 & $630,600 \mathrm{Aab}$ & $871,000 \mathrm{Aa}$ & $127,771 \mathrm{Babc}$ & $220,200 \mathrm{Aa}$ & $1054,133 \mathrm{Aa}$ \\
\hline P37 & $0,738 \mathrm{e}$ & $22,180 b$ & $0,228 \mathrm{c}$ & $628,335 a$ & $158,367 \mathrm{ab}$ \\
\hline P38 & $576,767 \mathrm{ab}$ & $653,867 a$ & $158,729 \mathrm{ab}$ & $244,557 \mathrm{a}$ & $323,300 a$ \\
\hline P47 & $589,300 \mathrm{ab}$ & $805,433 a$ & $147,128 \mathrm{abc}$ & $68,542 a$ & $584,933 \mathrm{ab}$ \\
\hline P78 & $84,543 \mathrm{ABd}$ & $922,000 \mathrm{Aa}$ & 23,716Bab & $7,801 \mathrm{Ba}$ & $1752,567 \mathrm{Aa}$ \\
\hline P79 & $1013,467 \mathrm{ab}$ & $988,200 a$ & $631,067 a$ & $192,733 a$ & $1842,673 a$ \\
\hline P80 & $72,097 d$ & $364,027 a$ & $33,119 a b c$ & $19,493 a$ & $763,167 a$ \\
\hline P82 & $853,500 \mathrm{ABab}$ & $1507,067 \mathrm{Aa}$ & $279,067 \mathrm{Ba}$ & $119,633 \mathrm{Ba}$ & $1776,433 \mathrm{Aa}$ \\
\hline P83 & $973,900 \mathrm{Bab}$ & $1810,100 \mathrm{ABa}$ & $580,367 \mathrm{Ba}$ & $675,967 \mathrm{Ba}$ & $2550,300 \mathrm{Aa}$ \\
\hline
\end{tabular}

Tabela 4 - Contagem de Unidades formadoras de colônia (UFC) por mL x $10^{6}$ de isolados de A. hydrophila em BHI, BHI + etanol 70\% e extratos etanólicos de própolis (verde, marrom do Estado do Ceará e Estado de Pernambuco) em 24 horas.

\begin{tabular}{lccccc}
\hline \multirow{2}{*}{ Isolado } & \multicolumn{5}{c}{24 horas } \\
\cline { 2 - 6 } & PMCE & PMPE & PV & Al & BHI \\
\hline P4 & $652,733 \mathrm{Cc}$ & $2890,700 \mathrm{Babcd}$ & $683,600 \mathrm{Cabc}$ & $866,000 \mathrm{Dab}$ & $3665,200 \mathrm{Aabc}$ \\
P8 & $219,933 \mathrm{Ed}$ & $3288,500 \mathrm{Aabc}$ & $18,820 \mathrm{Dd}$ & $817,800 \mathrm{Cab}$ & $1264,433 \mathrm{Bcde}$ \\
P18 & $3015,633 \mathrm{Aab}$ & $920,400 \mathrm{CEe}$ & $479,300 \mathrm{Eabc}$ & $1545,200 \mathrm{Bab}$ & $716,333 \mathrm{De}$ \\
P19 & $2701,400 \mathrm{Bab}$ & $6722,033 \mathrm{Aa}$ & $60,733 \mathrm{Dcd}$ & $2755,200 \mathrm{Aab}$ & $826,133 \mathrm{Bde}$ \\
P22 & $55,373 \mathrm{Be}$ & $14,613 \mathrm{Cf}$ & $0,240 \mathrm{De}$ & $66,863 \mathrm{Ac}$ & $59,163 \mathrm{Bf}$ \\
P25 & $1793,833 \mathrm{Cab}$ & $6018,000 \mathrm{Ba}$ & $465,700 \mathrm{Eabc}$ & $1478,233 \mathrm{Dab}$ & $9221,000 \mathrm{Aa}$ \\
P34 & $1566,333 \mathrm{abc}$ & $1543,200 \mathrm{cde}$ & $1512,850 \mathrm{a}$ & $695,500 \mathrm{abc}$ & $3148,800 \mathrm{bcde}$ \\
P37 & $2349,166 \mathrm{ab}$ & $2785,733 \mathrm{abcd}$ & $1145,933 \mathrm{ab}$ & $1301,500 \mathrm{ab}$ & $2035,000 \mathrm{bcde}$ \\
P38 & $1269,200 \mathrm{bc}$ & $1299,966 \mathrm{de}$ & $476,476 \mathrm{bcd}$ & $721,219 \mathrm{bc}$ & $1988,000 \mathrm{bcde}$ \\
P47 & $1735,933 \mathrm{abc}$ & $1474,866 \mathrm{cde}$ & $743,100 \mathrm{abc}$ & $1343,200 \mathrm{abc}$ & $2712,000 \mathrm{abcd}$ \\
P78 & $3458,400 \mathrm{ABa}$ & $4560,400 \mathrm{Aab}$ & $2167,899 \mathrm{Ba}$ & $3119,500 \mathrm{ABab}$ & $4710,000 \mathrm{Aab}$ \\
P79 & $4693,133 \mathrm{a}$ & $2740,767 \mathrm{bde}$ & $3559,933 \mathrm{a}$ & $4308,300 \mathrm{a}$ & $3935,600 \mathrm{abc}$ \\
P80 & $1692,667 \mathrm{AB}-$ & $1840,800 \mathrm{ABbde}$ & $1188,500 \mathrm{BCa}$ & $1030,400 \mathrm{Cab}$ & $1969,267 \mathrm{Abcde}$ \\
P82 & Cabc & $2595,833 \mathrm{bde}$ & $1719,367 \mathrm{ab}$ & $1390,200 \mathrm{ab}$ & $3952,933 \mathrm{abc}$ \\
P83 & $3463,367 \mathrm{ab}$ & $2007,033 \mathrm{bde}$ & $1838,100 \mathrm{a}$ & $2417,900 \mathrm{ab}$ & $2044,650 \mathrm{bcde}$ \\
\hline
\end{tabular}

No tempo de três horas, foram observadas diferenças significativas estatisticamente entre os controles $\mathrm{BHI}$ e $\mathrm{BHI}+$ etanol $70 \%$ e os tratamentos PV em seis isolados (40\%), PMCE em quatro isolados $(26,67 \%)$ e PMPE em quatro isolados $(26,67 \%)$. No tempo de 12 horas as diferenças estatisticamente significativas foram observadas entre os controles e as própolis em seis isolados (40\%) para as PV ePMCE e quatro isolados $(26,67 \%)$ para a PMPE (Tabela 3 ). Após 24 horas de incubação, diferenças estatísticas foram observadas nas contagens de UFC em seis isolados $(40 \%)$ para PV e quatro $(26,67 \%)$ isolados para PMCE e PMPE (Tabela 4).

Também foram observadas diferenças significativas no número de UFC obtidas após incubação com as diferentes propólis. A própolis verde apresentou as menores contagens na maioria dos tempos de avaliação, bem como nos diferentes isolados de $A$. hydrophila ( $80 \%$ em $3 \mathrm{~h}, 60 \%$ em $12 \mathrm{~h}$ e $66,67 \%$ em $24 \mathrm{~h}$ ). Além disso, a atividade antimicrobiana também variou entre os isolados de A. hydrophila analisados.

\section{DISCUSSÃO}

Todos os isolados de A. hydrophila testados foram sensíveis a diferentes concentrações de própolis. Variações são descritas no poder antimicrobiano da própolis frente a bactérias Gram positivas e Gram negativas (VARGAS et al., 2004; LOGUERCIO et al., 2006). As diferenças de sensibilidade podem estar associadas à composição da parede celular, sendo que as 
bactérias Gram positivas possuem várias camadas de peptideoglicano, enquanto que as Gram-negativas possuem uma camada fina e interna. Além desta camada, as bactérias Gram-negativas possuem uma membrana externa de lipopolissacarídeos e proteínas, o que dificulta a lise destas bactérias (Mirzoeva et al., 1997).

As CBMs obtidas nesse estudo foram maiores que a concentração de $80 \mu \mathrm{g} / \mathrm{mL}$ descrita por AzzA; ABD-EL-RHMAN (2009) com própolis do Egito frente a um isolado de Aeromonas spp. Como é bem conhecido, própolis de diferentes origens geográficas, em especial no Brasil e Europa, apresentam diferentes compostos químicos responsáveis pela atividade antimicrobiana (De Vecchi; Drago, 2007). Esses resultados divergentes podem estar relacionados à diferença da flora e clima entre Brasil (tropical ou subtropical) e Egito (temperado) (Orsi et al., 2007; Kujumgiev et al., 1999). As diferenças de sensibilidade à própolis, nos relatos da literatura, podem ser justificadas pelas variações na composição observadas das própolis de diferentes regiões, tipo de diluente e concentrações de teste (PARK et al., 2002; GARCIA et al., 2004b). Outros autores trabalhando com bactérias de interesse à saúde humana, animal e vegetal com diferentes concentrações de própolis obtiveram resultados diversos. BIANCHINI; BEDENDO (1998), ao verificar o efeito antimicrobiano de extrato aquoso de própolis a $10 \%$, observaram elevado percentual de sensibilidade de isolados de Erwinia chrysanthemi, enquanto que a Pseudomonas syringae pv. Tabaci mostrou-se resistente. VARGAS et al. (2004) encontraram sensibilidade em $42,5 \%$ das bactérias Gram-negativas testadas ao extrato alcoólico a $50 \%$ de própolis. Mirzoeva et al. (1997), utilizando a própolis para observar a sensibilidade de bactérias Gram negativas, concluíram que a própolis apresentou efeito antimicrobiano contra Rhodobacter sphaeroides e, portanto, seus resultados foram semelhantes aos obtidos neste estudo.

Quando analisados em conjunto, os resultados dos testes de CBM e da curva de sobrevivência podemos observar que a própolis verde apresentou maior potencial antimicrobiano diferindo das própolis marrons na maioria dos isolados avaliados. Estudos têm demonstrado que a própolis verde possui maior atividade antimicrobiana quando comparada com a marrom (SALANTINO et al., 2005; FARNESI et al., 2009).

O efeito antimicrobiano das própolis foi acentuado apenas nas três primeiras horas de incubação, indicando um efeito bacteriostático como recomendado por Cos et al. (2006) e pelo CLSI (2006). Além disso, a própolis verde apresentou maior redução nas contagens de UFC comparada com as própolis marrons. Estes resultados diferem de outros descritos na literatura, nos quais a própolis apresentou inibição total (efeito bactericida) de Staphylococcus aureus e Streptococcus agalactiae numa concentração de 3,0 e $2,0 \mathrm{mg} / \mathrm{mL}$ (PinTo, 2000) e Salmonella spp. em uma concentração de 8,54\% (Orsı et al., 2007). Resultados semelhantes aos deste trabalho foram descritos em Staphylococcus aureus por Lu et al. (2005), sendo que estes relacionaram a atividade da própolis com a fase decrescimento microbiano, maior na midi-log. Outra possibilidade seria a ocorrência de heteroresistência nos isolados, contudo requer confirmação. Ainda, houve diferenças entre os perfis de sobrevivência dos isolados, para um mesmo tratamento. Estes resultados indicam a importância do uso de várias amostras em particular de micro-organismos patogênicos para estudos desta natureza.

As diferenças entre os testes de atividade antimicrobiana realizados nesse estudo (CBM e curva de sobrevivência) são evidentes e podem estar associados ao volume de inóculo utilizado na cultura bacteriana após incubação. A escolha dos testes para busca da atividade antimicrobiana é muito importante, uma vez que dos seus resultados dependem a validação de um composto como antimicrobiano (Cosetal., 2006).Segundo HADACEK; GREGER (2000), os resultados de um teste de atividade antimicrobiana podem variar de acordo com o método escolhido, uma vez que a precisão de cada técnica é diferente.

Nas condições do presente estudo, conclui-se que os extratos etanólicos das três própolis avaliadas mostraram efeito bacteriostático contra os isolados de A. hydrophila.

\section{AGRADECIMENTOS}

À Associação dos Criadores de Abelha do Município de Petrolina (ASCAMP) pela doaçao das própolis brutas.

\section{REFERENNCIAS}

AKINBOWALE, O.L.; PENG, H.; BARTON, M.D. Antimicrobial resistance in bacteria isolated from aquaculture sources in Australia. Journal of Applied Microbiology, v.100, n.5, p.1103-1113, 2006.

AZZA, M.M.; ABD-EL-RHMAN. Antagonism of Aeromonas hydrophila by propolis and its effect on the performance of Nile tilapia, Oreochromis niloticus. Fish \& Shellfish Immunology, v.27, n.3, p.454-459, 2009.

BANSKOTA, A.H.; TEZUKA, Y.; ADNYANA, I.K.; MIDORIKAWA, K.; MATSUSHIGE, K.; MESSAGE, D.; HUERTAS, A.A.G.; KADOTA, S. Cytotoxic, hepatoprotective and free radical scavenging effects of propolis from Brazil, Peru, the Netherlands and China. Journal of Ethnopharmacology, v.72, n.1/2, p.239-246, 2000. 
BARJA, J.L.; ESTEVES, A.T. Enfermidades bacterianas. In: Patologia acuicultura. Espanha: Caicyt, 1988. 550p.

BIANCHINI, L.; BEDENDO, I.P. Efeito antibiótico da própolis sobre bactérias fitopatogênicas. Scientia Agricola, v.55, n.1, 1998.

BRASIL. Instrução Normativa n.3 de 19 de janeiro de 2001. Regulamentos Técnicos de Identidade e Qualidade de apitoxina, cera de abelha, geléia real, geléia real liofilizada, pólen apícola, própolis e extrato de própolis.

CABELLO, F.C. Heavy use of prophylactic antibiotics in aquaculture: a growing problem for human and animal health and for the environment. Environmental Microbiology, v.8, n.7, p.1137-1144, 2006.

\section{CLINICAL AND LABORATORY STANDARDS INSTI-} TUTE Performance standards for antimicrobial disk susceptibility testing. Approved standard M100-S17, 17th.ed. Wayne, Pa.: CLSI, 2006. Disponível em: <http:/ /www. clsi.org/>.

COS, P.; VLIETINCK, A.J.; BERGHE, D.V.; MAES, L. Anti-infective potential of natural products: How to develop a stronger in vitro 'proof-of-concept'. Journal of Ethnopharmacology, v.106, n.3, p.290-302, 2006.

COSTA, A.B. Caracterização de bactérias do complexo Aeromonas isoladas de peixes de água doce e sua atividade patogênica. 2003. 54f. Tese (Doutorado em Agronomia - Área de Concentração Ciência Animal e Pastagens) Universidade de São Paulo, Piracicaba, 2003.

CUETO, D.J. Experiência clínica de los medicamentos elaborados com propoleo. In: ASIS, M. (Ed.). Investigaciones cubanas sobre el propóleos. Memórias del $1^{\circ}$ Simpósio sobre los efectos del propoleo em la salud humana y animal. 1988. Varadero. Matanzas: Consejo Científico del Instituto de Medicina Veterinária, Cuba, 1989.

DE VECCHI, E.; DRAGO, L. Attività antimicrobica della propoli: casa c'è di nuovo. Le Infezioni in Medicina, n.1, p.7-15, 2007.

FARNESI, A.P.; AQUINO-FERREIRA, R.; DE JONG, D.; BASTOS, J.K., SOARES, A.E.E. Effects of stingless bee and honey bee própolis on four species of bacteria. Genetics and Molecular Research, v.8, n.2, p.635-640, 2009.

FRANCO, S.S.; ROSA, A.P.; LENGLER, S.; UTTPATEL, R.; ZANELLA, I., GRESSLER, C.; SOUZA, H.M. Índices produtivos e rendimento de carcaça de frangos de corte alimentados com dietas contendo níveis de extrato etanólico de própolis ou promotores de crescimento convencionais. Ciência Rural, v.37, n.6, p.1765-1771, 2007.

GARCIA, R.C.; SÁ, M.E.P.; LANGONI, H.; FUNARI, S.R.C. Efeito do extrato alcoólico de própolis sobre a Pasteurella multocida in vitro e em coelhos. Acta Scientiarum. Animal Sciences, v.26, n.1, p.69-77, 2004a.
GARCIA, R.C.; SÁ, M.E.P.; LANGONI, H.; FUNARI, S.R.C. Efeito do extrato alcoólico de própolis sobre o perfil bioquímico e o desempenho de coelhas jovens. Acta Scientiarum .Animal Sciences, v.26, n.1, p.57-67, 2004b.

HADACEK, F.; GREGER, H. Testing of antifungal natural products: Methodologies, comparability of results and assay of choice. Phytochemical Analysis, v.11, n.3, p.137-147, 2000.

KUJUMGIEV, A.; TSVETKOVA, I.; SERKEDJIEVA, Y.; BANKOVA, V.; CHRISTOV, R.; POPOV, S. Antibacterial antifungal and antiviral activity of propolis of different geographic origin. Journal of Ethnopharmacology, v.64, n.3, p.235-240, 1999 .

LOGUERCIO, A.P.; GROFF, A.C.M.; PEDROZZO, A.F.; WITT, N.M.; SILVA, M.S.; VARGAS, A.C. Atividade in vitro do extrato de própolis contra agentes bacterianos da mastite bovina. Pesquisa Agropecuária Brasileira, v.41, n.2, p.347-349, 2006

LU, L.; CHEN, Y.; CHOU, C. Antibacterial activity of propolis against Staphylococcus aureus. International Journal of Food Microbiology, v.102, p.213-220, 2005.

MARCUCCI, M.C.; FERRERES, F.; GARCÍA-VIGUERA, C.; BANKOVA, V.S.; CASTRO, S.L.de; DANTAS, A.P.; VALENTE, P.H.M.; PAULINO, N. Phenolic compounds from Brazilian propolis with pharmacological activities. Journal of Ethnopharmacology, v.74, n.2, p.105-112, 2001.

MIRZOEVA, O.K.; GRISHANIN, R.N.; CALDER, P.C. Antimicrobial action of propolis and some of its components: the effects on growth, membrane potencial and motility of bacteria. Microbiological Research, v.152, n.3, p.239-246, 1997.

ORSI, R.O.; SFORCIN, J.M.; FUNARI, S.R.C.; FERNANDES-JUNIOR, A.; RODRIGUES, P.; BANKOVA, V. Effects of propolis from Brazil and Bulgaria on Salmonella serovars. Journal of Venomous Animals and Toxins Including Tropical Diseases, v.13, n.4, p.748-757, 2007.

PARK, Y.K.; ALENKAR, S.M.; SCAMPARINI, A.R.P.; AGUIAR, C.L. Própolis produzida no sul do Brasil, Argentina e Uruguai: Evidências fitoquímicas de sua origem vegetal. Ciência Rural, v.32, n.6, p.997-1003, 2002

PINTO, M.S. Efeito antimicrobiano de própolis verde do estado de Minas Gerais sobre bactérias isoladas do leite de vacas com mastite. 2000. 104f. Dissertação (Mestrado em Medicina Veterinária Preventiva) - Universidade Federal de Viçosa, Viçosa, 2000.

PLUMB, J.A. Health maintenance and principal microbial diseases of cultured fishes. New York: CRC, 1994. 254p.

SAAVEDRA, M.J.; GUEDES-NOVAIS, S.; ALVES, A.; REMA, P.; TACÃO, M.; CORREIA, A.; MARTINEZMURCIA, A. Resistance to beta-lactam antibiotics in 
Aeromonas hydrophila isolated from rainbow trout (Oncorhynchus mykiss). International Microbiology, v.7, n.3, p.207-211, 2004.

SALANTINO, A.; TEIXEIRA, E.W.; NEGRI, G.; MESSAGE, D. Origin and chemical variation of Brazilian propolis. Evidence-based Complementary and Alternative Medicine, v.2, n.1, p.33-38, 2005.

SFORCIN, J.M.; FERNANDES-JUNIOR, A.; LOPES, C.A.M.; BANKOVA, V.; FUNARI, S.R.C. Seasonal effect of Brazilian propolis antibacterial activity. Journal of Ethnopharmacology, v.73, n.1/2, p.234-249, 2000.

TSUKAMOTO, R.Y.; TAKAHASHI, N.S. Falta de proteína para ração: estrangulamento da aqüicultura no Brasil. Panorama da Aquicultura, p.8-9, 1992.
VARGAS, A.C.; LOGUERCIO, A.P.; WITT, N.M.; COSTA, M.M.; SILVA, M.S.; VIANA, L.R. Atividade antimicrobiana "in vitro" de extrato alcoólico de própolis. Ciência Rural, v.34, p.159-163, 2004.

VERSCHUERE, L.; ROMBAUT, G.; SORGELOOS, P. Probiotic bactéria as biological control agents in aquaculture. Microbiology and Molecular Biology Reviews, v.64, n.4, p.655-671, 2000.

ZAR, J.H. Biostatistial analysis. 4.ed. 1999. 663p.

Recebido em 9/9/10

Aceito em 19/11/11 